\title{
Body size inequality in ground beetle (Coleoptera: Carabidae) assemblages as a potential method to monitor environmental impacts of transgenic crops
}

\section{DAVIDE DI GRUMO \\ GABOR L LÖVEI}

Department of Agroecology, Aarhus University Forsøgvej 1, 4200 Slagelse, Denmark

E-mail: gabor.lovei@agro.au.dk

Correspondence:

Gabor L. Lövei

E-mail: gabor.lovei@agro.au.dk

List of any nonstandard abbreviations

GM: Genetically Modified

GMOs: Genetically Modified Organisms

PMEM: Post Market Environmental Monitoring

GMCs: Genetically Modified Crops

Keywords: Lorenz asymmetry coefficient, Gini coefficient, monitoring, genetically modified crop, body length, inequality, MON810.
Received January 14, 2016.

Revised May 10, 2016.

Accepted May 16, 2016

\section{Abstract}

Background and Purpose: Despite the obligatory post-market environmental monitoring of genetically modified (GM) crops in Europe, there are no available methodological guidelines or standards. Our aim was to examine the suitability of carabid body size inequality as a possible method for environmental monitoring.

Material and Methods: We used carabids collected by pitfall traps in both insect-resistant GM (producing a Bacillus thuringiensis toxin) and isogenic maize plots at Flakkebjerg (Denmark), within the framework of the AMIGA Project. The body size distribution was calculated using various measures of size inequality: the Lorenz curve, the Gini and the Lorenz asymmetry coefficients every month during the summer 2014.

Results: A total of 6339 carabids belonging to 38 species were captured and identified. The analysis detected a significant shift in size inequality between months, indicating the larger number of individuals of smallersized species later in the season, but no significant difference in inequality or mean body size was found between the assemblages in GM vs. isogenic maize plots.

Conclusions: We concluded that the evaluation of body size inequality was sensitive to subtle changes in the structure of the carabid assemblages, and this method had the potential to be used during monitoring of the unanticipated environmental effects of GM plants.

\section{INTRODUCTION}

Cenetically modified crops (GMCs) have been grown under field $\mathbf{I}$ conditions since 1996 on a steadily increasing global area, with most of the growth restricted to certain regions (1). Despite almost twenty years of cultivation, the question whether the $B t$-expressing and other pest-resistant GMCs lead to increased or reduced environmental and human safety remains a highly controversial issue among scientists and GM crop regulators (2-5).

On one hand, there are arguments that this new technology has an overall positive impact on the environment, agricultural production and human health $(6,7)$, but a scientific consensus has not yet been reached (4). On the other hand, a range of case-specific potential risks has been 
identified at different levels of ecological complexity, for agricultural production systems and loss of „ecosystem services" (2-5). Apart from unwanted and unforeseen toxicological effects on so-called non-target organisms (NTOs) (2), ecosystem services could be affected (5) through indirect ecological interactions (8).

Thus, in addition to various pre-release biosafety tests, monitoring of the potential effects of GM organisms (GMOs) is important in order to detect effects that are not visible with short-time and small-scale experiments (9). For this reason, the EU Directive 2001/18/EEC affirms that Post Market Environmental Monitoring (PMEM) is a statutory requirement for the cultivation of GMCs in Europe (10). To date the European GMO regulatory system is one of most complete and articulate in the world (11), but there are no standardized approaches, methods or protocols in the European GMO monitoring guidance (12). The current AMIGA project (Assessing and Monitoring the Impacts of Genetically modified plants on Agro-ecosystems) is taking on these challenges (13). In particular, the aim of this project is to develop standards for effective PMEM designs for GMCs.

The most common error in monitoring is the lack of a match between the indicator and the indicandum, the phenomenon to be monitored or to be indicated (12). In this context, the indicandum is any substantial change in the status of the ecosystem in which the GMCs is grown.

As the indicator group, the ground beetles (Coleoptera: Carabidae) were selected. Carabids are a species-rich family of beetles, and many species are natural enemies of arthropods or weeds. Ground beetles are numerous and widespread in arable habitats all over the world (14) and are frequently used in environmental monitoring (15).

There can be various parameters (indices) to be used to detect the impact of the growing of a GMC on carabids. Most frequently, changes in the composition and abundance of the species are evaluated (15). This requires expertise to identify species, and this is not always available. An additional problem is also the difficulty of comparing various assemblages. When is, for example one assemblage significantly more diverse than another one, and what is the appropriate index to test this?

Looking for an alternative, we considered body size, which is notably correlated with several biological traits (16), including dispersal capacity, reproduction rate and development time, and some potential indirect impacts (e.g. period of activity). Body size also influences ecological interactions (e.g. competition and habitat suitability), resource utilization and many other parameters (17). Therefore, changes in body size inequality in various assemblages can be a potentially useful parameter.

Szyszko (18) hypothesised that during forest succession, the mean size of individual carabids would increase, because larger species appear later during the succession.
Both natural and anthropogenic disturbance has the potential to alter the inequality of body sizes, towards a dominance of smaller species in highly stressed habitats (17, 19-21). According to the "decreasing body size hypothesis", a ground beetle assemblage under unfavourable environmental conditions will change so that small-size generalist and eurytopic species will increase their abundance, while large specialist species with poor dispersing ability will decrease (17).

We tested body size distribution of ground beetle assemblages as a possible monitoring method that could reflect any potential adverse effect of CrylAb toxin on the selected bioindicator, ground beetles. Here we show that several body size inequality measures are suitably sensitive to reflect changes in the assemblage during the season. They can also be statistically tested, and thus are useful for monitoring purposes.

\section{MATERIAL AND METHODS}

\section{Study site}

The field trial was carried out on the experimental farm

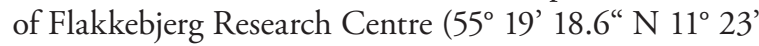
$25.1^{\prime \prime} \mathrm{E} ; 30 \mathrm{~m}$ a.s.l.), in the western part of the island of Zealand (Denmark), from June to August 2014. Following the AMIGA protocol (13), a field of 0.5 ha was randomly divided into ten plots of Bt-maize (MON810) and ten plots of its parental isogenic line, serving as controls. Each plot measured 10x9 m and was surrounded by a $5 \mathrm{~m}$ strip of bare ground. The field was surrounded by barley. The ground was characterised by clayey soil, with $50 \%$ of clay fraction, $45 \%$ sand and $5 \%$ humus (U. Pilegaard, Aarhus University, personal communication).

\section{Carabid collection methods}

The ground beetles were sampled by pitfall traps ( 500 $\mathrm{ml}$ plastic cups of $10 \mathrm{~cm}$ diameter), filled with $100 \mathrm{ml}$ of $70 \%$ ethylene glycol as a killing-preserving agent and a drop of odourless detergent to reduce surface tension. The cups were placed in the middle of each plot, in order to avoid edge effects, and sunk into the ground, such that their rim was level with the soil surface. A straight plastic barrier connected two such traps, placed $1 \mathrm{~m}$ from each other. Individual traps were covered by a $20 \times 20 \mathrm{~cm}$ galvanised metal sheet, about $2 \mathrm{~cm}$ above the soil surface, in order to minimise the catch of undesired species (e.g. small vertebrates), potential debris and the accumulation of rainwater. Traps were open from June to August, one week per month (9-16 June, 7 - 14 July, 5 - 12 August). After every collection, we inactivated the pitfalls by plugging the traps with a plastic cover and pushing down the covers, to prevent additional captures during the three weeks of non-sampling. All captured carabids were identified to species using keys by Lindroth $(22,23)$ and 
Hurka (24) plus a reference collection housed at the Department of Agroecology.

\section{Analysis of carabid body size distribution}

Body size data for each species were taken from the literature $(22,23)$. We calculated the geometric mean of the minimum-maximum values, as in previous studies (17). The „decreasing body size hypothesis" was tested using the Lorenz curve (25), a traditional graphical measure describing inequality of body size pattern.

In this graphical approach, individuals are ranked by size and the cumulative proportion of carabid individuals is plotted against the corresponding cumulative proportion of their total size $(17,26)$. When all individuals are of the same size, the Lorenz curve follows the diagonal line, the „line of equality” (Fig. 1). Any difference in size forces the curve below this line.

\section{Gini coefficient}

To quantify size inequality, the most common summary statistic is the Gini coefficient (27). If the data are ordered by increasing body size, the Gini coefficient is calculated as

$$
G=\frac{\sum_{i=1}^{n}(2 i-n-1) x_{[i]}}{n^{2} \bar{x}}
$$

where $n$ is the number of individuals, $x_{[i]}$ is the ordered body size of individuals $i$ and $\bar{x}$ is the mean body size (28). The Gini coefficient, calculated by the above equation should be multiplied with $n /(n-1)$ to become an unbiased estimate (29). The Gini coefficient can then be thought of as the area that lies between the line of equality and the Lorenz curve, with coefficient values ranging from $G=0$ (complete equal distribution) to a theoretical maximum of $\mathrm{G}=1$ (complete inequality) (28).

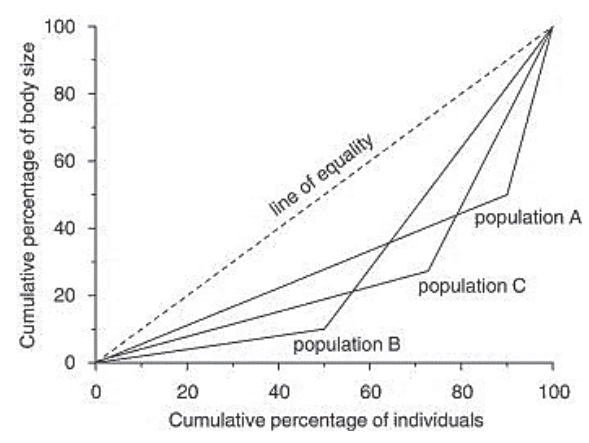

Figure 1. Lorenz curves of three hypothetical populations. All populations have the same Gini coefficient, but different Lorenz asymmetry coefficients (S). In the case of the population $A, S>1$, in the population $B, S<1$, while in population $C$ is symmetric $(S=1)$. After Magura et al. (17)

\section{Lorenz asymmetry coefficient}

This statistic does not contain all the information in the Lorenz curve (25), because different Lorenz curves can have the same Gini coefficient (as the three curves on Fig. 1. do). The Lorenz asymmetry coefficient (S) can be calculated using the following equation (25):

$$
S=F(\hat{x})+L(\hat{x})=\frac{m+\delta}{n}+\frac{L_{m}+\delta x_{m+1}^{\prime}}{L_{n}}
$$

where

$$
\delta=\frac{\bar{x}-x_{m}^{\prime}}{x_{m+1}^{\prime}-x_{m}^{\prime}}
$$

$\bar{x}$ and $n$ are the same as in Eq. $1, m$ is the number of individuals with a body size $<\bar{x}, L_{m}$ is the cumulative body size of individuals with a body size $<\bar{x}$, and $L_{n}$ is the cumulative body size of all individuals.

When $S=1$, the Lorenz curve is symmetric. If $S>1$, the point where the tangent to the Lorenz curve is parallel with the line of equality is above the axis of symmetry, caused by the presence of large individuals (25). If $S<1$, then that point falls below the axis of symmetry and the inequality is primarily due to the relatively large number of small individuals (Fig. 1). These indices were tested to evaluate changes in body size distribution of ground beetles along an urbanisation gradient (17), and the Lorenz curve performed best.

To compare the Gini and Lorenz asymmetry coefficients between GM and conventional maize crops, the normal distribution of data was tested by the KolmogorovSmirnov test and the Shapiro-Wilk normality test. Both proved that our data are normally distributed, so a linear mixed effects model for repeated measures data (lme) with plots as random effects was adopted. This model was chosen over more traditional approaches, such as repeated measures ANOVA, because of its ability to deal with missing values and pertinence in settings where repeated measurements are carried out on the same statistical units (30). The analyses were carried out using the $\mathrm{R}$ package (31), the internal packages ,ineq” for the coefficient (32), „lattice” for graphs (33) and „nlme” (34) for statistical analysis.

\section{RESULTS}

A total of 6339 carabids belonging to 38 species were identified (Table 1). The dominant species was the mixed feeder Harpalus rufipes (De Geer, 1774). Among the most abundant species, the genus Bembidion was well represented by three species, B. lampros (Herbst, 1784), $B$. obtusum (Audinet-Serville, 1821) and B. properans (Stephens 1828). There were some larger and common species such as Anchomenus dorsalis (Pontoppidan, 1763), Stomis pumicatus (Panzer 1796) and Pterostichus melanarius (Illiger 1798) and a small one, Trechus quadristriatus (Schrank 1781). 
These eight dominant species made up $88.8 \%$ of the total numbers captured. The dominance was not different between the Bt- and isogenic maize plots. The GM plots had a higher number of species per month (mean $=22.33$ and S.D. $=1.15)$ than the isogenic ones (mean $=20.67$ and S.D. = 2.31). There were 12 singleton species, of which 4 were captured in the isogenic and 8 in the GM maize plots.

\section{Body size distribution}

The species ranged in size from $3.13 \mathrm{~mm}$ to $23.29 \mathrm{~mm}$ (Table 1). The body size distribution profile (Fig. 2) did not show any obvious difference between assemblages in Bt- and isogenic maize plots. However, at the beginning of the season, the carabid assemblages had a lower mean body size $\left(\operatorname{mean}_{\mathrm{GM}}=5.82\right.$, S.D. $=3.69$ vs. mean $_{\mathrm{ISO}}=6.5$, S.D. $=4.06$ ), in particular by high numbers of $B$. lampros and $B$. properans. The only large species with high activity was $H$. rufipes. In July, medium sized species increased in activity density $\left(\right.$ mean $_{\mathrm{GM}}=7.86$, S.D. $=3.96$ vs. mean $_{\mathrm{ISO}}=$ 8.09, S.D. $=4.05$ ). In August, activity density of large species increased, further increasing the mean body size $\left(\operatorname{mean}_{\mathrm{GM}}=10.12\right.$, S.D. $=4.35$ vs. mean $_{\mathrm{ISO}}=9.77$, S.D. $=$ 4.34), in particular H. rufipes, $P$. melanarius and $P$. niger, and a decrease of the small species that were dominant in June.

The Gini coefficient was generally low (Fig. 3), indicating two carabid assemblages with similar inequalities of body size. The coefficient was highest in the isogenic maize plots in June $\left(\mathrm{G}_{\mathrm{GM}}=0.28\right.$, S.D. $=0.05$ vs. $\mathrm{G}_{\mathrm{ISO}}=$
0.3, S.D. $=0.02)$ and August $\left(\mathrm{G}_{\mathrm{GM}}=0.23\right.$, S.D. $=0.02$ vs. $\mathrm{G}_{\mathrm{ISO}}=0.25$, S.D. $\left.=0.03\right)$, but similar to GMO in July $\left(\mathrm{G}_{\mathrm{GM}}=0.27\right.$, S.D. $=0.02$ vs. $\mathrm{G}_{\mathrm{ISO}}=0.28$, S.D. $\left.=0.02\right)$, suggesting that body size inequality of carabid assemblages was slightly larger in the isogenic maize assemblages. The Gini coefficient indicated marginally significant $(\mathrm{p}<0.1)$ differences between the two treatments (Table 2). The Gini coefficient was significantly different ( $\mathrm{p}<0.0001)$ between months.

The Lorenz asymmetry coefficients were generally similar between the two treatments, indicating two carabid assemblages with similar distribution of body size inequality. The coefficient was $S<1$ for both treatments over the whole season $\left(\mathrm{S}_{\mathrm{GM}}=0.95\right.$, S.D. $=0.29$ vs. $\mathrm{S}_{\mathrm{ISO}}=$ 0.92 , S.D. $=0.2$ ), suggesting that asymmetry was mostly caused by small species.

Looking at each month, the coefficient was decreasing in both the Bt- and isogenic maize plots (Fig. 4). It had values $S>1$ for June $\left(S_{\mathrm{GM}}=1.18\right.$, S.D. $=0.25$ vs. $S_{\mathrm{ISO}}=1.06$, S.D. $=0.18$ ), suggesting the importance of larger individuals for the skewness of the Lorenz curve. In July, the value was very close to $S=1$ in both treatments $\left(S_{\mathrm{GM}}=1.04\right.$, S.D. $=0.16$ vs. $S_{\text {ISO }}=0.98$, S.D. $=0.12$ ). This is typical of a nearly symmetric Lorenz curve. In August, in both maize plots, Lorenz asymmetry coefficients were $S<1\left(\mathrm{~S}_{\mathrm{GM}}=\right.$ 0.64 , S.D. $=0.13$ vs. $S_{\text {ISO }}=0.74$, S.D. $\left.=0.14\right)$, indicating the contribution of small individuals to asymmetry.

However, the differences in the Lorenz asymmetry coefficients among the studied areas were not significant

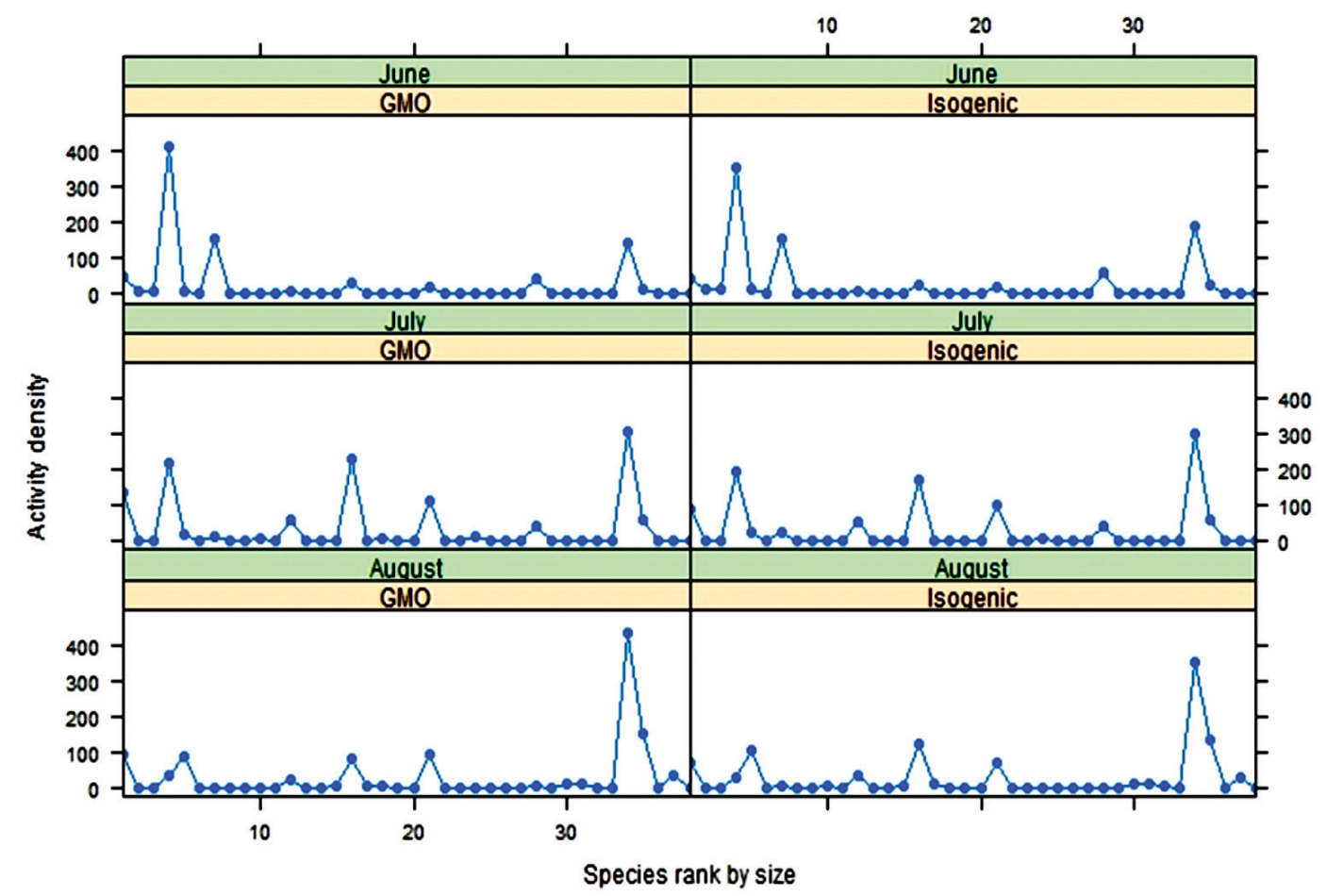

Figure 2. Trend of activity density of the carabid species captured, comparing treatments and months. Species (x-axis) are arranged according to increasing body size. 
Table 1. Total number of ground beetles individuals captured over three months. Species are arranged by increasing body size. The body size is a geometric mean calculated from, and nomenclature follows Lindroth $(22,23)$.

\begin{tabular}{|c|c|c|c|c|c|c|c|c|}
\hline \multirow[b]{3}{*}{ Species } & \multicolumn{8}{|c|}{ Number of individuals captured } \\
\hline & \multirow{2}{*}{$\begin{array}{l}\text { Body size } \\
(\mathrm{mm})\end{array}$} & \multicolumn{2}{|c|}{ June } & \multicolumn{2}{|c|}{ July } & \multicolumn{2}{|c|}{ August } & \multirow[b]{2}{*}{ Total } \\
\hline & & GMO & Isogenic & GMO & Isogenic & GMO & Isogenic & \\
\hline Bembidion obtusum & 3.13 & 51 & 42 & 137 & 91 & 96 & 70 & 487 \\
\hline Bembidion quadrimaculatum & 3.13 & 10 & 11 & 3 & 0 & 0 & 0 & 24 \\
\hline Acupalpus meridianus & 3.54 & 8 & 12 & 0 & 3 & 0 & 0 & 23 \\
\hline Bembidion lampros & 3.63 & 414 & 357 & 218 & 198 & 39 & 30 & 1256 \\
\hline Trechus quadristriatus & 3.74 & 7 & 12 & 18 & 23 & 90 & 107 & 257 \\
\hline Trechus secalis & 3.74 & 0 & 0 & 1 & 0 & 0 & 0 & 1 \\
\hline Bembidion properans & 3.83 & 152 & 155 & 15 & 24 & 3 & 6 & 355 \\
\hline Notiophilus aestuans & 4.69 & 1 & 2 & 0 & 0 & 0 & 0 & 3 \\
\hline Bradycellus verbasci & 4.84 & 0 & 0 & 0 & 0 & 1 & 0 & 1 \\
\hline Demetrias atricapillus & 5.02 & 4 & 0 & 6 & 3 & 4 & 7 & 24 \\
\hline Paradromius linearis & 5.14 & 0 & 0 & 0 & 0 & 0 & 1 & 1 \\
\hline Bembidion tetracolum & 5.47 & 7 & 5 & 63 & 56 & 26 & 35 & 192 \\
\hline Notiophilus biguttatus & 5.48 & 0 & 0 & 0 & 0 & 1 & 0 & 1 \\
\hline Oxypselaphus obscurus & 5.74 & 0 & 0 & 0 & 1 & 0 & 0 & 1 \\
\hline Clivina fossor & 5.98 & 1 & 1 & 0 & 1 & 5 & 5 & 13 \\
\hline Anchomenus dorsalis & 7.01 & 32 & 27 & 231 & 174 & 81 & 125 & 670 \\
\hline Synuchus vivalis & 7.14 & 0 & 0 & 7 & 4 & 6 & 4 & 21 \\
\hline Loricera pilicornis & 7.14 & 0 & 0 & 1 & 0 & 6 & 11 & 18 \\
\hline Calathus melanocephalus & 7.27 & 0 & 0 & 1 & 1 & 1 & 2 & 5 \\
\hline Amara aenea & 7.39 & 1 & 0 & 0 & 0 & 0 & 0 & 1 \\
\hline Stomis pumicatus & 7.51 & 18 & 22 & 114 & 100 & 98 & 71 & 423 \\
\hline Amara apricaria & 7.65 & 0 & 0 & 1 & 0 & 0 & 0 & 1 \\
\hline Ophonus rufibarbis & 7.67 & 0 & 0 & 0 & 1 & 0 & 0 & 1 \\
\hline Agonum muelleri & 8.27 & 1 & 2 & 12 & 6 & 4 & 3 & 28 \\
\hline Amara consularis & 8.67 & 0 & 1 & 2 & 2 & 0 & 0 & 5 \\
\hline Harpalus tardus & 9.61 & 1 & 0 & 0 & 0 & 0 & 0 & 1 \\
\hline Calathus erratus & 10.01 & 1 & 0 & 0 & 0 & 0 & 0 & 1 \\
\hline Harpalus affinis & 10.10 & 44 & 63 & 44 & 45 & 5 & 2 & 203 \\
\hline Poecilus cupreus & 10.48 & 1 & 1 & 0 & 0 & 0 & 0 & 2 \\
\hline Harpalus melancholicus & 10.49 & 0 & 1 & 0 & 0 & 13 & 13 & 27 \\
\hline Nebria brevicollis & 11.83 & 0 & 0 & 0 & 0 & 14 & 12 & 26 \\
\hline Calathus fuscipes & 12.00 & 0 & 0 & 1 & 2 & 1 & 5 & 9 \\
\hline Amara aulica & 12.54 & 0 & 0 & 1 & 0 & 1 & 3 & 5 \\
\hline Harpalus rufipes & 12.92 & 142 & 187 & 309 & 299 & 437 & 355 & 1729 \\
\hline Pterostichus melanarius & 14.70 & 13 & 27 & 61 & 60 & 154 & 138 & 453 \\
\hline Dolichus halensis & 16.43 & 0 & 0 & 1 & 0 & 0 & 0 & 1 \\
\hline Pterostichus niger & 17.54 & 1 & 0 & 3 & 1 & 35 & 29 & 69 \\
\hline Carabus nemoralis & 23.92 & 0 & 0 & 0 & 1 & 0 & 0 & 1 \\
\hline \multicolumn{2}{|c|}{ Total number of individuals captured } & 910 & 928 & 1250 & 1096 & 1121 & 1034 & 6339 \\
\hline \multicolumn{2}{|l|}{ Total number of species captured } & 21 & 18 & 23 & 22 & 23 & 22 & \\
\hline
\end{tabular}




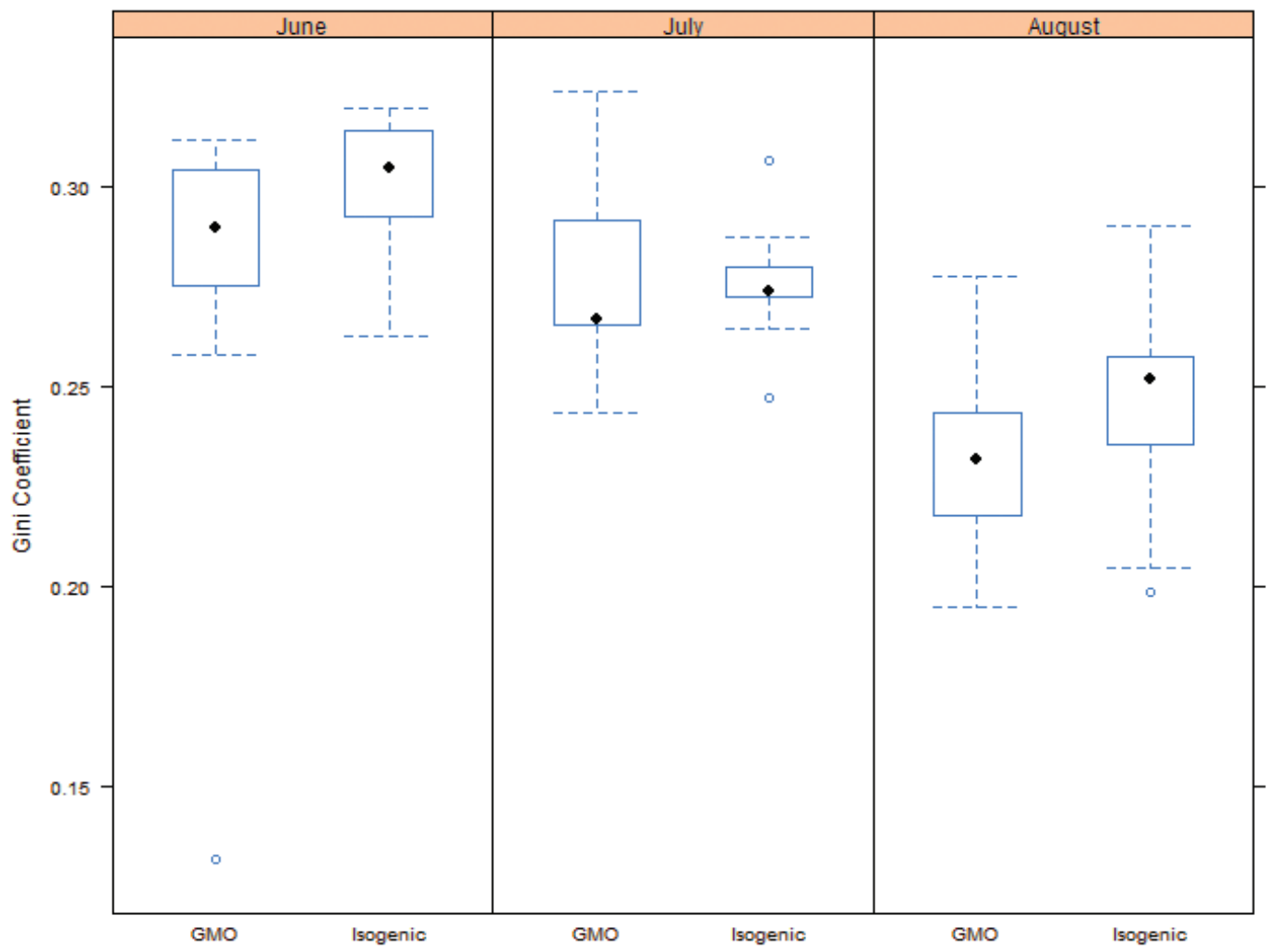

Figure 3. Variation of the Gini coefficient between GM and isogenic maize plots over three summer months, in Flakkebjerg, 2014. The black dot indicates the median, the box marks the central quartile; ranges are denoted by broken lines.

(Table 2). The only highly significant effect $(\mathrm{p}<0.0001)$ was the seasonality („month”) as in the Gini coefficient values.

\section{DISCUSSION}

In the present case study on the impacts of Bt(MON810) maize on agro-ecosystem, we had two main goals. The first was to produce a basic checklist of carabid species in the agro-ecosystem in Flakkebjerg (Denmark) as a basis for a more effective PMEM. The second main goal was the assessment of the potential of the size distribution asymmetry as a parameter in monitoring the effects of GMCs on selected NTOs, the ground beetles.

The „decreasing body size hypothesis” has been extensively tested in studies on carabid fauna $(17,19,21)$, but so far not in relation to GM environmental effects. The results suggested no effect of the maize crop, whether GM or its isogenic equivalent, on carabid body size inequality.

Table 2. Analysis with a linear mixed effect model for Gini and Lorenz asymmetry coefficient on treatment (GMO vs. isogenic) and month (June vs. July vs. August) for carabid body size inequality. Plots are the random effects.

\begin{tabular}{|lcccc|}
\hline & numDF & denDF & F-value & p-value \\
\hline Gini coefficient & & & & \\
\hline Month & 2 & 36 & 14.401 & $<0.0001$ \\
Treatment & 1 & 18 & 3.086 & $0.096^{*}$ \\
Month: Treatment & 2 & 36 & 0.725 & 0.491 \\
\hline Lorenz asymmetry coefficient & & 36 & 34.102 & $<0.0001$ \\
Month & 2 & 18 & 0.468 & 0.503 \\
Treatment & 1 & 36 & 2.105 & 0.137 \\
Month: Treatment & 2 & & & \\
\hline
\end{tabular}

*Possible biological $(\mathrm{p}<0.10)$ but not significant $(\mathrm{p}<0.05)$ treatment effect. 
However, an increasing body size trend from June to August was evident, and both indices reflected the increasing activity density of larger species as the season progressed and according to the different phenology of the dominant species (spring or autumn breeders).

Analysing the Lorenz curve, no significant differences in inequality were found between $\mathrm{Bt}$ - and non-Bt maize fields. The only marginally significant differences were obtained by the use of the Gini coefficient. This parameter suggested that body size inequality of carabid assemblages was slightly larger in isogenic maize assemblages respect to the GM one.

Several papers used the Gini coefficient to measure inequality in size or biomass, but the biological interpretation of skewness of a distribution is difficult (25) and it is referred to the total amount of size inequality. Nevertheless, it may be useful to look at not only the overall degree of inequality between treatments, but also how this inequality is distributed. The Gini coefficient does not have the power to distinguish what causes the deviation from perfect evenness (25).

As in the case of examining the effect of urbanisationrelated disturbance on ground beetle assemblages in Hungary (17), the inequality in carabid body size was much easier to biologically interpret using the Lorenz asymmetry coefficient. It was transparent that the skewness of Lorenz curve was sensitive to the seasonal changes of body size classes and not the treatments. Magura et al. (17) as well as earlier studies considered the whole year or season together, while we looked at a finer level of analysis, which proved fruitful. We were able to detect a significant impact of the season on body size asymmetry in carabid assemblages, indicating the sensitivity of the method for monitoring purposes.

We conclude that these methods, and in particular the Lorenz asymmetry coefficient, were indeed sensitive to subtle seasonal changes in the structure of the carabid assemblages, and they indicated no important differences between the structural composition, body size inequality and diversity of ground beetles in GM (MON810) vs. isogenic maize in Denmark at this spatial scale.

Work at species level was important to better discriminate the phenology that in this case study mainly indicated seasonal variations, and exclude the risk for some species to be suppressed by Bt maize and replaced by other less sensitive species. Furthermore, surveys covering the whole activity season are necessary, in order to completely investigate the seasonal variation of ground beetles.

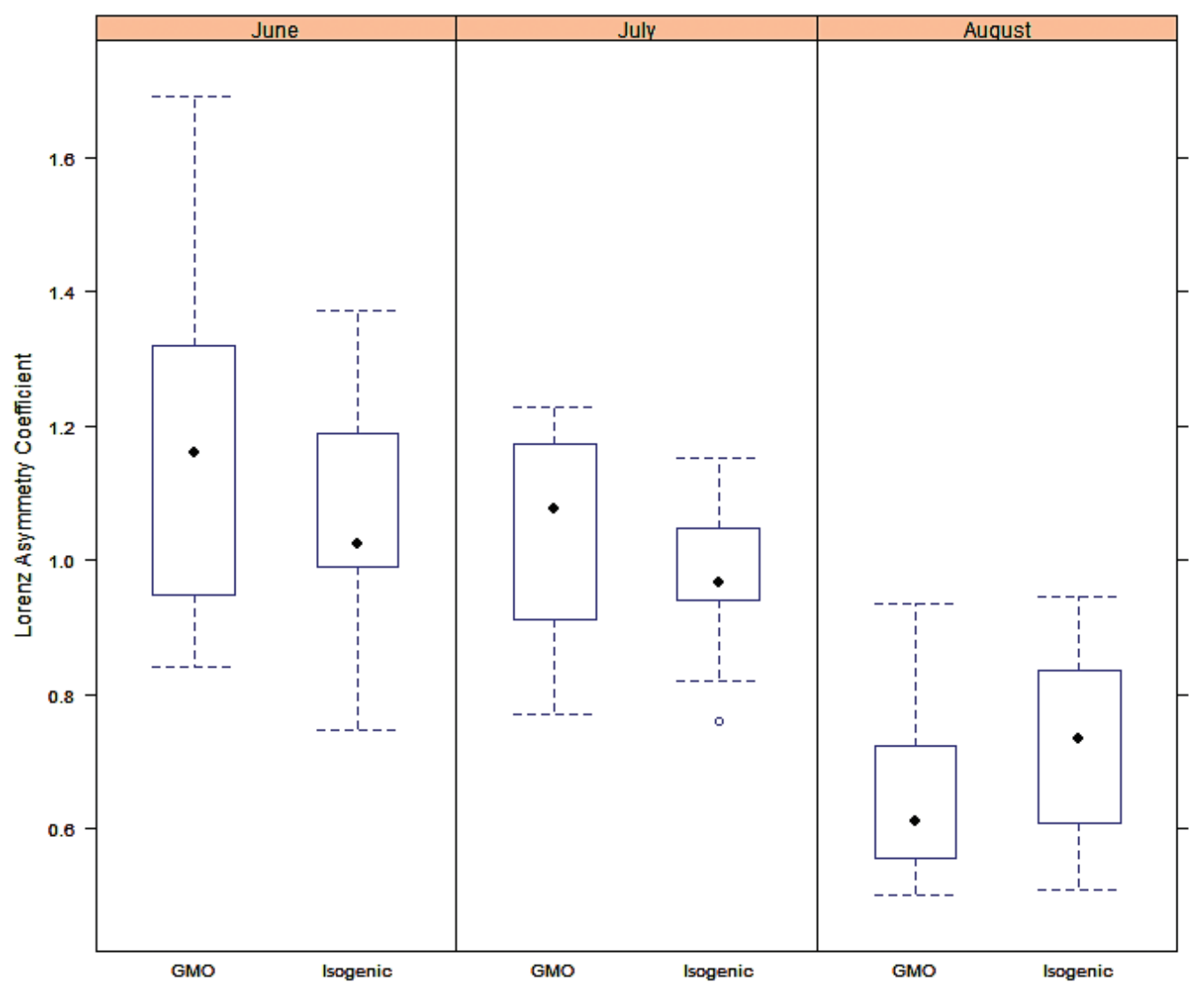

Figure 4. Variation (presented as Box-plots) of Lorenz asymmetry coefficients between GM and isogenic plots over three summer months, in Flakkebjerg, 2014. The black dot indicates the median, the box marks the central quartile; ranges are denoted by broken lines. 
Acknowledgements: We thank N. Patelli and A. Lo Cacciato for help during the fieldwork, M. Ferrante for help with the statistical analysis, and two anonymous reviewers for comments on the manuscript. This work is scientific output No. 14 of the AMIGA project, funded by the European Commission under grant agreement $n^{\circ} 289706$.

\section{REFERENCES}

1. JAMES C 2012 Global Status of Commercialized Biotech/GM Crops: 2012: ISAAA Brief No 44 Ithaca, NY

2. ARPAIA S 2010 Genetically modified plants and "non-target" organisms: analysing the functioning of the agro-ecosystem. Collection of Biosafety Reviews 5: 12-80

3. BIRCH A N E, WHEATLEY R E 2005 GM pest-resistant crops: Assessing environmental impacts on lion-target organisms. Issues in Environmental Science and Technology 21: 31-57 http://dx.doi.org/10.1039/9781847552433-00031

4. HILBECK A, BINIMELIS R, DEFARGE N, STEINBRECHER R, SZÉKÁCS A, WICKSON F, ANTONIOU M, BEREANO P L, CLARK E A, HANSEN M 2015 No scientific consensus on GMO safety. Environmental Sciences Europe 27:4 http://dx.doi.org/10.1186/s12302-014-0034-1

5. LÖVEI G L 2001 Ecological risks and benefits of transgenic plants. New Zealand Plant Protection 54: 93-100 https://www.nzpps.org/journal/54/nzpp_540930.pdf

6. GULLAN P J, CRANSTON P S 2005 The insects: an outline of entomology. 3rd edition: Wiley-Blackwell, Oxford, 505. pp.

7. SCHNEPF E, CRICKMORE N., VAN RIE J, LERECLUS D, BAUM J, FEITELSON J, ZEIGLER D R, DEAN D H 1998 Bacillus thuringiensis and its pesticidal crystal proteins. Microbiology and Molecular Biology Reviews 62: 775-806

8. ANDOW D A, ZWAHLEN C 2006 Assessing environmental risks of transgenic plants. Ecology Letters 9: 196-214

9. BARDOCZ S, PUSZTAI A 2007 Post-commercialization testing and monitoring (or post-release monitoring) for the effects of transgenic plants. In Traavik T, Ching LL (eds) Biosafety First - Holistic Approaches to Risk and Uncertainty in Genetic Engineering and Genetically Modified Organisms. Tapir University Press, Trondheim, pp. 507-520

10. EFSA 2011 Scientific Opinion on guidance on the Post-Market Environmental Monitoring (PMEM) of genetically modified plants. EFSA Journal 9(2316): 40

11. HUSBY J 2007 A general introduction to the regulation of GMOs and gene technology. In Traavik T, Ching LL (eds) Biosafety First - Holistic Approaches to Risk and Uncertainty in Genetic Engineering and Genetically Modified Organisms. Tapir University Press, Trondheim, pp. 351-373

12. LÖVEI G L 2014 On monitoring. Journal of Biosafety 23: 1-3 doi: 10.3969/j.issn.2095-1787-2014.01.001

13. ARPAIA S, MESSÉAN A, BIRCH N, HOKANNEN H, HÄRTEL S, VAN LOON J, LÖVEI G L, PARK J, SPREAFICO H, SQUIRE G 2014 Assessing and monitoring impacts of genetically modified plants on agro-ecosystems: the approach of AMIGA project. Entomologia 2: 79-86 http://dx.doi.org/10.4081/entomologia.2014.154

14. LÖVEI G L, SUNDERLAND K D 1996 Ecology and behavior of ground beetles (Coleoptera: Carabidae). Annual Review of Entomology 41: 231-256 http://dx.doi.org/10.1146/annurev.en.41.010196.001311

15. RAINIO J, NIEMELA J 2003 Ground beetles (Coleoptera: Carabidae) as bioindicators: Biodiversity and Conservation 12: 487506 http://dx.doi.org/10.1023/A:1022412617568
16. PETERS R H 1986 The ecological implications of body size, Cambridge University Press, Cambridge, 329 pp.

17. MAGURA T, TOTHMERESZ B, LÖVEI G L 2006 Body size inequality of carabids along an urbanisation gradient. Basic and Applied Ecology 7: 472-482 http://dx.doi.org/10.1016/j.baae.2005.08.005

18. SZYSZKO J 1983 State of Carabidae (Col.) fauna in fresh pine forest and tentative valorisation of this environment. Warsaw Agricultural University Press, Warsaw, 80 pp.

19. GARBALINSKA P, SKLODOWSKI J 2008 Body size differentiation in selected carabid species inhabiting Puszcza Piska forest ecosystems disturbed by the hurricane in 2002. Sylwan 152: 3-15

20. LÖVEI G L, MAGURA T 2006 Body size changes in ground beetle assemblages - a reanalysis of Braun et al. (2004)'s data. Ecological Entomology 31: 411-414

21. ULRICH W, KOMOSINSKI K, ZALEWSKI M 2008 Body size and biomass distributions of carrion visiting beetles: do cities host smaller species? Ecological Research 23: 241-248 http://dx.doi.org/10.1007/s11284-007-0369-9

22. LINDROTH C H 1985 The Carabidae Coleoptera of Fennoscandia and Denmark. Fauna Entomologica Scandinavica Vol. 15 Part 1. E. J. Brill: Leiden, Netherlands; Scandinavian Science Press Ltd.: Copenhagen, Denmark, 227 pp.

23. LINDROTH C H 1986 The Carabidae Coleoptera of Fennoscandia and Denmark. Fauna Entomologica Scandinavica, Vol. 15, Part 2. E. J. Brill/ Scandinavian Science Press Ltd.: Leiden, Netherlands; Copenhagen, Denmark, 265 pp.

24. HURKA K 1996 Carabidae of the Czech and Slovak Republics, Kabourek, Zlin, 565 pp.

25. LORENZ M O 1905 Methods of measuring the concentration of wealth. Publications of the American Statistical Association 9: 209219 http://dx.doi.org/10.2307/2276207

26. DAMGAARD C, WEINER J 2000 Describing inequality in plant size or fecundity. Ecology 81: 1139-1142 http://dx.doi.org/10.1890/ 0012-9658(2000)081[1139:DIIPSO]2.0.CO;2

27. GINI C 1914 Sulla misura della concentrazione e della variabilità dei caratteri. In Pizetti E, Salvemini T (eds), Atti della III Riunione della Societa Italiana per il Progresso delle Scienze. Memorie di Metodologia Statistica, Vol. 1 Eredi Virgilio Veschi, Rome, pp. 411-459

28. DIXON P M, WEINER J, MITCHELLOLDS T, WOODLEY R 1987 Bootstrapping the Gini coefficient of inequality. Ecology 68: $1548-1551$

29. GLASSER G J 1962 Variance formulas for the mean difference and coefficient of concentration. Journal of the American Statistical Association 57: 648-654 http://dx.doi.org/10.1080/01621459.1962.10500553

30. LINDSTROM M J, BATES D M 1990 Nonlinear mixed effects models for repeated measures data. Biometrics 46: 673-687 http://dx.doi.org/10.2307/2532087

31. R CORE TEAM $2014 \mathrm{R}$ : A language and environment for statistical computing: R Foundation for Statistical Computing, Vienna, Austria. http://www.R-project.org/.

32. ZEILEIS A 2014 ineq: Measuring Inequality, Concentration, and Poverty: R package version 0.2-13. http://CRAN.R-project.org/ package $=$ ineq.

33. SARKAR D 2008 Lattice: multivariate data visualization with $R$, Springer Science \& Business Media, 283 pp. http://dx.doi.org/10.1007/978-0-387-75969-2

34. PINHEIRO J, BATES D, DEBROY S, SARKAR D, R Core Team 2014 nlme: Linear and Nonlinear Mixed Effects Models. R package version 3.1-117, URL http://CRAN.R-project.org/package=nlme 